\title{
PENGEMBANGAN FORMULASI MIKROEMULSI MINYAK SEREH (Cymbopogon nardus) MENGGUNAKAN EMULGATOR SURFAKTAN NONIONIK
}

\author{
A.Hasrawati'), Nursiah Hasyim²), Nur Alif Irsyad ${ }^{1)}$ \\ ${ }^{1)}$ Universitas Muslim Indonesia \\ 2) Universitas Hasanuddin \\ Email : a.hasrawati@umi.ac.id
}

\begin{abstract}
Citronella oil (Cymbopogon nardus) is an essential oil which useful as an antibacterial that is usually provided in the form of macroemulsion for topical use. absorption of macroemulsion through the skin relatively low, thermodynamically is not stable and can produce a separate phase in the storage period. The one of development emulsion system to get better characteristics is to form a microemulsion. Microemulsion is an oil and water dispersion stable thermodynamically stabilized by surfactants and in some cases a cosurfactant. The objective of this study was to formulatecitronella oil in the form of a stable microemulsion using nonionic surfactant. Optimization of the type and amount of emulsifier (surfactant) was required to formulate a stable microemulsion. In this study, microemulsion was evaluated during a month. Type and concentration of surfactant, cosurfactant, Citronella oil (Cymbopogon nardus) and water was optimized. A stable citronella oil microemulsion was successfully created with composition of 15\% PEG 400 as cosurfactant, 15\% tween 80 as surfactant, 2-4\% Citronella oil as oil phase and 10\% glycerin as humectant and distilled water as aqueous phase. From the observation, microemulsion formula has clear appearance but physically unstable during a month storage.
\end{abstract}

Keywords: microemulsion, Citronella oil, nonionic surfactant

\section{PENDAHULUAN}

Tanaman penghasil minyak atsiri dapat digunakan sebagai bahan antioksidan yang potensial, antimikroba serta aromaterapeutik dalam kosmetik dan penggunaan farmasi yang menarik minat masyarakat karena meningkatnya kekhawatiran tentang potensi efek samping zat aditif sintetik (Kim, 2009).

Minyak sereh adalah minyak atsiri yang diperoleh dengan penyulingan uap daun Cymbopogon nardus Rendle (Cymbopogon winterianus Jewitt) atau varietas dan hibrida kedua species tersebut, mengandung tidak kurang dari $21 \%$ dan tidak lebih dari 35\% sitronelal dan tidak kurang dari 10\% dan tidak lebih dari 18\% geraniol (Ditjen POM, 1979).

Kumar dkk. (2009) mengkaji efek minyak atsiri dari 15 varietas tanaman serai terhadap 10 mikroorganisme patogen yang berbeda dan didapatkan hasil bahwa seluruh varietas tanaman serai tersebut memiliki tingkat sensitivitas yang tertinggi. Menurut uswatun (2011) minyak atsiri pada sereh memiliki aktivitas antimikroba terhadap bakteri Listeria monocytogenes, Salmonella typhimurium, Escherichia colli, Shigella dysenteria, Bacillus cereus, dan Staphylococcus aureus.

Hasil penelitian yang telah dilakukan Masniari Poeloengan (2009), bahwa minyak sereh atau daun sereh (Cymbopogon nardus) menunjukkan aktivitas antimikroba terhadap bakteri uji Jurnal Fitofarmaka Indonesia, Vol. 3 No.1
Staphylococcus aureus dengan konsentrasi 12,5\% dan Staphylococcus epidermidis dengan konsentrasi 6,25 $\%$ dan $12,5 \%$.

Minyak atsiri biasanya tersedia dalam bentuk makroemulsi dan digunakan dengan mengencerkannya dengan berbagai jenis minyak nabati dan alkohol untuk penggunaan topikal yang memiliki usia simpan dan absorbsi pada kulit yang relatif rendah dan tidak stabil secara termodinamika serta dapat menghasilkan fase terpisah pada masa penyimpanan. Untuk mengatasi masalah tersebut dikembangkan sistem penghantaran obat yang baru dan relatif lebih efektif seperti mikroemulsi (Kim, 2009).

Mikroemulsi merupakan suatu sistem dispersi yang dikembangkan dari sediaan emulsi. Bila dibandingkan dengan emulsi, banyak karakteristik dari mikroemulsi yang membuat sediaan ini menarik untuk digunakan sebagai salah satu sistem penghantaran obat (drug delivery system). Antara lain mempunyai kestabilan dalam jangka waktu lama secara termodinamika, jernih dan transparan, mempunyai daya larut yang tinggi serta mempunyai kemampuan berpenetrasi yang baik. (Mahdi, 2004).

Berdasarkan pertimbangan inilah yang mendasari pengembangan formulasi mikroemulsi minyak sereh (Cymbopogon nardus).

Untuk menghasilkan mikroemulsi diperlukan konsentrasi yang tinggi dari emulgator 151 
(biasanya 10\% - 40\%) untuk menurunkan tegangan antarmuka dari suatu sistem menuju nol (Sprowls, 1970). Jenis dan konsentrasi emulgator (surfaktan) harus dioptimasi untuk mendapatkan formula mikroemulsi yang stabilitasnya optimum. Pada umumnya surfaktan nonionik dipilih karena toleransi perkutannya baik, potensi iritasi dan toksisitas yang lebih rendah (Grampurohit, 2011)

\section{METODE PENELITIAN}

\section{A. Alat}

Botol $100 \mathrm{ml}$, gelas piala (iwaki,Pyrex), gelas ukur (iwaki,Pyrex), lemari pendingin (Modenna), magnetic stirer (Thermolyne), oven (Memmert), penangas air, magic processor (CNI), pipet volume, pipet tetes, $\mathrm{pH}$ meter (Eutech $\mathrm{pH} 700$ ), sentrifus (Onemed), timbangan analitik (Ohaus), termometer (Pyrex), viskometer RVT(Brookfield).

\section{B. Bahan}

Minyak sereh (Cymbopogon nardus), sorbitan monooleat, polisorbat 80, PEG 400, dan air suling.

\section{Prosedur Penelitian \\ 1. Pembuatan Mikroemulsi}

Langkah-langkah pembuatan mikroemulsi minyak adalah : memisahkan fase minyak dan fase air. Fase minyak dibuat dengan mencampurkan minyak sereh dengan emulgator larut minyak. Fase air dibuat dengan mencampurkan air, emulgator larut air, kosurfaktan dan humektan. Kemudian kedua fase dipanaskan, fase air hingga $73{ }^{\circ} \mathrm{C}$ sedangkan fase minyak pada suhu $70{ }^{0} \mathrm{C}$ lalu fase minyak dimasukkan kedalam fase air dan diaduk menggunakan magic prosessor selama 5 menit.

\section{Optimasi Jenis dan Konsentrasi Surfaktan dan Kosurfaktan}

Emulgator yang digunakan adalah polisorbat 80 dan sorbitan monoleat. Pengujian terbentuknya mikroemulsi dilakukan dengan membuat beberapa seri formula mikroemulsi dengan variasi konsentrasi surfaktan nonionik (5-15\%). Kosurfaktan yang digunakan adalah PEG 400 dengan konsentrasi 10 $15 \%$.

\section{Optimasi Konsentrasi Minyak Sereh}

Optimasi konsentrasi minyak sereh dilakukan setelah diperoleh hasil dari optimasi jenis surfaktan. Minyak sereh digunakan dalam sediaan obat maupun kosmetik adalah 2 hingga $10 \%$.

\section{Pembuatan dan Evaluasi Kestabilan Mikroemulsi}

Formula mikroemulsi yang dibuat dengan memvariasikan konsentrasi emulgator surfaktan nonionic, Kemudian dilakukan serangkaian uji untuk mengevaluasi kestabilannya, antara lain :

\section{Uji Sentrifugasi}

Sediaan mikroemulsi dimasukkan kedalam tabung sentrifugasi kemudian dilakukan pengocokan atau sentrifugasi pada kecepatan $3000 \mathrm{rpm}$ selama 30 menit (Mahdi, 2006).

\section{Uji Viskositas}

Pengukuran dilakukan dengan viskometer Brookfield dengan kecepatan 2rpm, 4rpm, 10rpm, 20 rpm. Data yang diperoleh diplotkan terhadap tekanan geser $\left(\right.$ dyne $\left./ \mathrm{cm}^{2}\right)$ dan kecepatan geser (rpm) sehingga didapat sifat aliran (rheology) (Mahdi, 2006).

\section{Penyimpanan Pada Suhu Kamar}

Formula mikroemulsi sebanyak $100 \mathrm{ml}$ ditempatkan dalam gelas kimia, lalu disimpan pada suhu kamar selama 7 hari lalu diuji organoleptis yang meliputi kejernihan dan translucent, bau, rasa dan warna. Uji viskositas dilakukan dengan menggunakan Brookfield dengan kecepatan $50 \mathrm{rpm}$.

\section{Uji Freeze - Thaw}

Evaluasi stabilitas fisik dengan metode freeze-thaw ditentukan dengan menyimpan sediaan tidak kurang dari 48 jam pada suhu $4^{\circ} \mathrm{C}$, lalu dilihat ada atau tidaknya pemisahan fase. Selanjutnya disimpan pada suhu $40^{\circ} \mathrm{C}$ selama 48 jam, dan dilihat ada tidaknya pemisahan fase. Pengujian dilakukan selama 6 siklus, yaitu satu siklus terdiri dari 48 jam pada kulkas $4^{\circ} \mathrm{C}$ dan 48 jam kemudian pada oven $40^{\circ} \mathrm{C}$ (Gozali D, 2009).

\section{Uji pH}

Pengukuran $\mathrm{pH}$ dilakukan dengan menggunakan $\mathrm{pH}$ meter digital dengan cara elektroda pada $\mathrm{pH}$ meter digital dicelupkan kedalam sediaan mikroemulsi hingga $\mathrm{pH}$ meter menunjukkan angka yang stabil. Pengukuran dilakukan pada suhu kamar pada awal dan akhir penyimpanan.

\section{HASIL DAN PEMBAHASAN}

\section{A. Pembuatan Mikroemulsi}

Penelitian ini terdiri dari dua tahap pembuatan yakni pertama percobaan pendahuluan dengan tujuan menentukan kondisi dan komposisi bahan yang sesuai untuk menghasilkan sediaan mikroemulsi yang jernih dan stabil, meliputi kecepatan pengadukan, temperatur dan lama pengadukan. Konsentrasi fase minyak, surfaktan dan fase air juga harus diperhatikan.

\begin{tabular}{llr}
\multicolumn{2}{c}{ Mikroemulsi dapat dibuat dengan } \\
pengadukan. Proses pengadukan dapat
\end{tabular} mendispersikan fase terdispersi. Hal ini disebabkan karena energi kinetik yang diberikan dapat menyebabkan fase terdispersi terpecah menjadi globul-globul kecil. Lamanya waktu pengadukan juga mempengaruhi hasil akhir mikroemulsi. Jika terlalu 
lama, mikroemulsi akan menjadi keruh. Karena tetesan yang terdapat dalam mikroemulsi saling berbenturan dan membentuk tetesan yang lebih besar, sehingga mikroemulsi menjadi tidak stabil dan terjadi pemisahan fase. Jika pengadukan terlalu singkat, mikroemulsi juga menjadi keruh karena terjadi penggumpalan bahan-bahan yang tidak homogen (Mahdi, 2009).

Surfaktan yang digunakan dalam sistem mikroemulsi ini adalah surfaktan nonionik yang relatif aman karena toksisitas dan sifat mengiritasinya rendah. Walaupun demikian harus diperhatikan temperatur yang digunakan. Pada suhu rendah, surfaktan nonionik menjadi lebih hidrofilik dan membentuk sistem M/A. Pada suhu tinggi, bersifat lipofilik dan membentuk sistem A/M. Pada suhu menengah, yang disebut sebagai suhu HLB, interaksi hidrofilik -lipofilik menjadi seimbang (Swarbrick, 2007)

Pada tahap optimasi jenis dan konsentrasi surfaktan diperoleh formula yang menggunakan polisorbat 80 sebagai surfaktan tunggal pada konsentrasi $15 \%$ membentuk sediaan yang jernih dan stabil.

Tahap kedua yaitu optimasi konsentrasi kosurfaktan, diperoleh sediaan mikroemulsi yang stabil pada konsentrasi $15 \%$. Penambahan kosurfaktan selain dapat menurunkan tegangan antarmuka minyak-air, juga dapat meningkatkan fluiditas antarmuka sehingga dapat meningkatkan entropi sistem. kosurfaktan juga dapat meningkatkan mobilitas ekor hidrokarbon sehingga penetrasi minyak pada bagian ekor menjadi lebih besar (Mahdi, 2006).

Tahap ketiga, optimasi konsentrasi minyak sereh dengan variasi konsentrasi 2-10\%. Pemilihan konsentrasi ini didasarkan pada konsentrasi minyak sereh yang tersedia dalam sediaan yang beredar dipasaran. Sediaan yang jernih diperoleh pada konsentrasi minyak sereh 2-7\%. Namun, pada konsentrasi $5-7 \%$ dalam beberapa hari penyimpanan sediaan menjadi keruh dan terjadi pemisahan fase.

Tabel 1. Formula mikroemulsi minyak sereh untuk optimasi jenis dan konsentrasi surfaktan, cosurfaktan dan minyak sereh

\begin{tabular}{|c|c|c|c|c|c|c|}
\hline \multirow{2}{*}{ No. } & \multirow{2}{*}{ Bahan } & \multicolumn{5}{|c|}{ Konsentrasi (\%b/v) } \\
\hline & & F1 & F2 & F3 & F4 & F5 \\
\hline $\mathbf{1}$ & Minyak sereh & 2 & 2 & 2 & 2 & $2-10$ \\
\hline 2 & Polisorbat 80 & $5-15$ & - & \multirow{2}{*}{$5-15$} & 15 & 15 \\
\hline 3 & Sorbitan monoleat & - & $5-15$ & & - & - \\
\hline 4 & PEG 400 & 15 & 15 & 15 & $10-15$ & 15 \\
\hline 5 & Gliserin & 10 & 10 & 10 & 10 & 10 \\
\hline 6 & Air suling ad & 100 & 100 & 100 & 100 & 100 \\
\hline
\end{tabular}

\section{B. Uji Organoleptis}

Sediaan mikroemulsi yang diuji organoleptis adalah sediaan yang tedapat pada suhu kamar dan uji Freeze - Thaw. Sediaan mikroemulsi diamati organoleptisnya yang meliputi warna, bau, kejernihan dan endapan yang terbentuk selama penyimpanan. Hasil pengujian pada suhu kamar menunjukkan warna kuning pada semua sediaan, bau khas minyak sereh dengan penampilan jernih dan tanpa endapan. Sedangkan untuk pengujian pada Suhu $4^{\circ} \mathrm{C}$ menunjukkan penampilan translucent pada formula III.pada suhu $40^{\circ} \mathrm{C}$ hanya formula III yang menunjukkan penampilan jernih.

\section{Uji Sentrifugasi}

Sediaan mikroemulsi yang diuji sentrifugasi adalah sediaan yang terdapat pada suhu $4^{\circ} \mathrm{C}, 27^{\circ} \mathrm{C}$ dan $40^{\circ} \mathrm{C}$. Sediaan disentrifugasi dengan kecepatan $3000 \mathrm{rpm}$ selama 30 menit. Setelah disentrifugasi formula I, II, dan III tetap stabil.

\section{Uji Viskositas}

Sediaan mikroemulsi yang diuji viskositasnya adalah sediaan yang tedapat pada suhu kamar dan uji Freeze - Thaw. Sediaan mikroemulsi diuji baik sebelum maupun setelah kondisi dipaksakan.

Tabel 2. Hasil pengukuran viskositas dari sediaan mikroemulsi minyak sereh pada suhu kamar dan freeze-thaw dengan kecepatan $50 \mathrm{rpm}$ 


\begin{tabular}{cccccccc}
\hline \multirow{2}{*}{ Kondisi } & \multirow{2}{*}{ Replikasi } & \multicolumn{4}{c}{ Suhu Kamar $\left(\mathbf{2 7}^{\circ} \mathbf{C}\right)$} & \multicolumn{3}{c}{ Freeze-Thaw } \\
\cline { 2 - 8 } & & $\mathbf{A 1}$ & $\mathbf{A 2}$ & $\mathbf{A 3}$ & $\mathbf{A 1}$ & $\mathbf{A 2}$ & $\mathbf{A 3}$ \\
\hline \multirow{3}{*}{ Sebelum } & 1 & 0,144 & 0,133 & 0,144 & 0,144 & 0,133 & 0,144 \\
\cline { 2 - 8 } & 2 & 0,145 & 0,133 & 0,142 & 0,145 & 0,133 & 0,142 \\
\hline \multirow{3}{*}{ Setelah } & 3 & 0,145 & 0,134 & 0,145 & 0,145 & 0,134 & 0,145 \\
\cline { 2 - 8 } & 1 & 0,185 & 0,174 & 0,196 & 0,187 & 0,211 & 0,211 \\
\cline { 2 - 8 } & 2 & 0,182 & 0,175 & 0,197 & 0,188 & 0,208 & 0,21 \\
\hline
\end{tabular}

\section{E. Uji pH}

Sediaan mikroemulsi yang diuji $\mathrm{pH}$ adalah sediaan yang terdapat pada suhu kamar dan uji Freeze - Thaw. Sediaan mikroemulsi diuji sebelum dan setelah kondisi dipaksakan. Dari hasil pengamatan ketiga formula menunjukkan penurunan $\mathrm{pH}$. Penurunan $\mathrm{pH}$ terjadi karena gliserin merupakan alkohol polihidris yang mudah teroksidasi. Bila teroksidasi, gliserin dapat menghasilkan asam karboksilat. Asam karboksilat tersebut dapat menurunkan $\mathrm{pH}$. Jika suhu dinaikkan, kecepatan reaksi ini semakin meningkat (Mahdi, 2009). Sehingga disimpulkan bahwa ketiga formula tidak stabil karena mengalami reaksi yang menyebabkan terjadinya penurunan $\mathrm{pH}$ yang sangat drastis.

\section{KESIMPULAN}

Berdasarkan hasil penelitian dapat disimpulkan bahwa mikroemulsi minyak sereh (Cymbopogon nardus) pada konsentrasi 2, 3 dan 4\% dapat terbentuk dengan menggunakan emulgator nonionik tunggal yaitu menggunakan polisorbat 80 sebagai emulgator dengan konsentrasi 15\%, PEG 400 sebagai kosurfaktan dengan konsentrasi $15 \%$ dan gliserin sebagai humektan pada konsentrasi $10 \%$ serta aquadest sebagai fase airnya. Namun, dari ketiga formula tidak didapatkan formula yang stabil setelah penyimpanan.

\section{DAFTAR PUSTAKA}

Kim, S. 2009. Microemulsion Formulation of Natural Plant Oils for Topical Delivery.

Direktorat Jenderal POM, 1979, Farmakope Indonesia, Edisi III, Jakarta : Departemen Kesehatan RI.

Uswatun, N,. 2011. Analisis Minyak Atsiri Serai (Cymbopogon citratus) Sebagai Alternatif Bahan Irigasi Saluran Akar Gigi Dengan
Menghambat

Pertumbuhan

Enterococcus faecalis. Semarang: Dosen Fakultas Kedokteran Gigi UNISSULA.

Mahdi., J., dkk. 2004. Formulasi Gameksan Dalam Bentuk Mikroemulsi. Majalah Ilmu Kefarmasian, Vol. I, no.3, 160-174. (http:/journal.lib.ui.ac.id/index.php/article/v iew/1061) Diakses pada tanggal 21 April 2012

Mahdi., J., 2006, Uji Stabilitas Sediaan Mikroemulsi Menggunakan Hidrolisat Pati (DE 35 40) Sebagai Stabilizer., Jakarta : FMIPA UI

Sprowl, J., (1970), Prescription Pharmacy $2^{\text {nd }}$ edition.Philadelphia : J.B. Lippincott Company

Grampurohit,N, Padmini, R.,and Rashmi, M.,2009. Microemulsions For Topical Use - A Review. Indian Journal of Pharmaceutical Education and Research

Gozali D, D Rusmiati \&P Utama. 2009. Formulasi dan Uji Stabilitas Mikroemulsi Ketokonazol Sebagai Antijamur Candida albicans dan Tricophyton mentagrophytes. Farmaka, Volume 7 nomor 2, Agustus 2009. Jatinangor : Universitas Padjadjaran

Mahdi., J., 2009. Pembuatan Mikroemulsi dari Minyak Buah Merah.Majalah Ilmu Kefarmasian, Vol. VI, no.1, 18-27. Diakses pada tanggal 22 september 2012.

Swarbrick, J,. 2007. Encyclopedia of pharmaceutical Technology, Third Edition.Pinehurst, North Carolinia, USA :. PharmaceuTech. Inc. 